TITLE:

\title{
Effects of litter type, origin of isolate, and temperature on decomposition of leaf litter by macrofungi
}

$\operatorname{AUTHOR}(\mathrm{S}):$

Osono, Takashi

\section{CITATION:}

Osono, Takashi. Effects of litter type, origin of isolate, and temperature on decomposition of leaf litter by macrofungi. Journal of Forest Research 2014, 20(1): 77-84

\section{ISSUE DATE:}

2014-09-05

URL:

http://hdl.handle.net/2433/200282

\section{RIGHT:}

The final publication is available at Springer via http://dx.doi.org/10.1007/s10310-0140462-1.; This is not the published version. Please cite only the published version.; この論 文は出版社版でありません。引用の際には出版社版をご確認ご利用ください。 
1 Effects of litter type, origin of isolate, and temperature on decomposition of leaf

2 litter by macrofungi

3

4 Takashi Osono

5

6 T. Osono

7 Center for Ecological Research, Kyoto University, Otsu, Shiga 520-2113 Japan

8 e-mail: tosono@ecology.kyoto-u.ac.jp

9

10 AbstractThe dependence of hyphal growth and litter decomposition on litter type

11 and incubation temperature used as substratum was compared for

12 litter-decomposing macrofungi (LDM) originating from subtropical (ST), cool

13 temperate (CT), and subalpine forests (SA) in Japan. In the first series of pure

14 culture decomposition tests using a total of 39 litter types as substrata inoculated

15 with six fungal isolates from the three climatic regions, the fungal decomposition

16 of litter was negatively affected by the content of AUR or extractives and

17 positively by $\mathrm{N}$ content in the litter. Secondly, cross-inoculation tests were 
18 performed to examine the mass loss of leaf litter of broad-leaved trees from ST, CT,

19 and SA, each inoculated with three Mycena species from the three climates and

20 incubated at seven temperatures between $5^{\circ} \mathrm{C}$ and $35^{\circ} \mathrm{C}$. Fungal isolate, litter

21 type, incubation temperature, and their interactions significantly affected the

22 mass loss of litter during the incubation. The greatest values of mass loss were

23 found at $20^{\circ} \mathrm{C}$ or $25^{\circ} \mathrm{C}$, and were generally consistent with the optimum

24 temperatures of colony diameter growth rate of these isolates. Isolates from cooler

25 regions were more sensitive to higher temperature than isolates from warmer

26 regions. The decomposition of recalcitrant compounds (as acid-unhydrolyzable

27 residues, AUR) by Mycena sp. from ST was also affected by litter type and

28 incubation temperature, but the degree of selective decomposition of AUR relative

29 to other components, such as cellulose, was insensitive to the range of

30 temperature tested.

31

32 Keywords Acid-unhydrolyzable residue • Temperature • Leaves •

33 Litter-decomposing macrofungi · Selective delignification 
35

36

37

38

39

40

41

42

43

44

45

46

47 recalcitrant compounds, such as lignin, under constant laboratory conditions and found that the decomposing abilities were variable among LDM species within a

51 climatic region but that the variability in decomposing ability was relatively 
52 similar among climatic regions (Osono submitted). These results led to a further

53 hypothesis that the decomposing ability of LDM originating from different

54 climates varies in its sensitivity to temperature and litter quality. Several studies

55 have examined the dependence of fungal decomposition on incubation

56 temperature and/or the quality of leaf litter (Lindeberg 1946; Mikola 1956;

57 Miyamoto et al. 2000; Osono and Takeda 2006; Osono et al. 2011c). To the

58 knowledge of the author, however, few studies have explored chemical components

59 that can limit fungal decomposition and compared the dependence of

60 decomposition on temperature and litter types between major LDM originating

61 from regions with different climatic conditions (Osono 2011).

The purpose of the present study was to assess under pure culture

63 conditions the dependence of fungal growth and decomposition on litter types

64 used as substrata, incubation temperature, and the origin of the isolate. I used six

65 isolates of LDM species, five of which belonged to Mycena, obtained in subtropical,

66 cool temperate, and subalpine forests in Japan because (i) they occurred as

67 fruiting bodies most frequently on the forest floor of the respective forests (Osono

68 in press b) and (ii) they exhibited the greatest activity of the LDM isolates to 
69 decompose leaf litter (Osono submitted). I performed two pure culture tests that

70 manipulated litter types and incubation temperature. First, a total of 39 litter

71 types and six fungal isolates from the three climatic regions were used to examine

72 possible limiting factors of fungal decomposition (denoted as the litter types test).

73 Secondly, the pure culture decomposition tests were designed to evaluate the

74 effects of litter type, incubation temperature, Mycena isolates of different origins,

75 and the interactions of these factors on the decomposition of leaf litter and

76 recalcitrant compounds in the litter (denoted as the cross inoculation test).

\section{Materials and methods}

80 Study site

82 Isolates of macrofungi and litter materials used in pure culture decomposition

83 tests were collected at three sites in Japan: a subtropical (ST), a cool temperate

84 (CT), and a subalpine (SA) forest. ST was located in an evergreen broadleaved

85 forest in the northern part of Okinawa Island. CT was located in a deciduous 
86 broadleaved forest in Kyoto. SA was located in an evergreen coniferous forest in

87 Gifu. The mean annual temperature was $22^{\circ} \mathrm{C}, 10^{\circ} \mathrm{C}$, and $2^{\circ} \mathrm{C}$ in $\mathrm{ST}$, CT, and SA, respectively. The study sites received similar amounts of precipitation annually

89 (approximately $2500 \mathrm{~mm}$ ). Further details about the location, climatic condition,

90 vegetation, and properties of the forest floor are given in Osono (in press a, in

91 press b).

92

93 Fungal isolates

95 Six isolates were used, two isolates from each of the three study sites: two unidentified Mycena species (denoted as Mycena sp.1 MAFF241586 and Mycena sp.2 MAFF241604) from ST, Mycena polygramma IFO33011 and an unidentified

98 Clitocybe species from CT, and Mycena aurantiidisca O2_07101503b and $M$.

99 epipterygia O9_07101508 from SA. The Mycena species were the macrofungal

100 taxa most frequently encountered as fruiting bodies at each study site (Osono in

101 press b) and were active decomposers of leaf litter (Osono submitted). Clitobybe sp.

102 fruited at low frequency in CT (Osono in press b) and was a selective decomposer 
103 of recalcitrant compounds on the forest floor (Osono et al. 2011a). These

104 macrofungal isolates were obtained from tissues of fruiting bodies collected at the

105 study sites (Osono submitted), and maintained on slants of 1\% malt extract agar

106 medium [MEA, malt extract $1 \%$ and agar $2 \%(\mathrm{w} / \mathrm{v})]$ at $20^{\circ} \mathrm{C}$ in darkness until the

107 tests were performed. Mycena sp.1 and sp.2 from ST were analyzed for base

108 sequences of the rRNA gene 28S D1/D2 (accession numbers: AB512383 for

109 Mycena sp.1 and AB512392 for Mycena sp.2), but identification to species level

110 was not successful.

112 Litter materials

113

114 Newly shed leaves of 12,15 , and 12 plant species without obvious fungal or faunal

115 attack were collected from the surface of the forest floor in January to April 2008,

116 November 2000, and October 2009 in ST, CT, and SA, respectively (see Table S1 in

117 Electronic Supplementary Material) and used for the litter type test. For the cross

118 inoculation test, newly shed leaves of Castanopsis sieboldii, Fagus crenata, and

119 Betula ermanii without obvious fungal or faunal attack were collected from the 
120 surface of the forest floor of ST, CT, and SA at peak periods of litter fall in April

121 2009, October 2009, and October 2009, respectively. The litters were oven-dried at

$12240^{\circ} \mathrm{C}$ for one week and preserved in vinyl bags for one to two months until the

123 experiments were started.

124

125 Litter type test

127 The effect of litter type on decomposition was examined under pure culture

128 conditions in the litter type test. Two isolates each from ST, CT, or SA were

129 inoculated onto 12 , 15 , or 12 litter types that differed in chemical composition

130 collected at ST, CT, or SA, respectively.

132 isolate inoculated to one litter type. Litter ( $0.3 \mathrm{~g})$ was sterilized by exposure to

133 ethylene oxide gas at $60^{\circ} \mathrm{C}$ for 6 hours and used in the tests, according to the

134 methods described in Osono et al. (2011c). The sterilized litters were placed on the

135 surface of Petri dishes (9 cm diameter) containing $20 \mathrm{ml}$ of $2 \%$ agar. Inocula for

136 each assessment were cut out of the margin of previously inoculated Petri dishes 
137 on 1\% MEA with a sterile cork borer (6 $\mathrm{mm}$ diameter) and placed on the agar

138 adjacent to the litter, one plug per plate. The plates were incubated for 12 weeks

139 in the dark at $20^{\circ} \mathrm{C}$. The plates were sealed firmly with laboratory film during

140 incubation so that moisture did not limit decomposition on the agar. After

141 incubation the litters were retrieved, oven-dried at $40^{\circ} \mathrm{C}$ for 1 week, and weighed.

142 The initial, undecomposed litters were also sterilized, oven-dried at $40^{\circ} \mathrm{C}$ for 1

143 week, and weighed to determine the original mass. Three to four plates were

144 prepared for each isolate, and four uninoculated plates served as a control. Mass

145 loss of litter was determined as a percentage of the original mass, taking the mass

146 loss of litter in the uninoculated and incubated control treatment into account,

147 and the mean values were calculated for each plate. Prior to the tests, the

148 sterilized litters were placed on $1 \% \mathrm{MEA}$, and after 8 weeks of incubation at $20^{\circ} \mathrm{C}$

149 in darkness, no microbial colonies had developed on the plates. Thus, the

150 effectiveness of the sterilization method used in the present study was verified.

151 The initial litters of multiple tree species were analyzed for the contents of

152 acid-unhydrolyzable residues (AUR), total carbohydrates, extractives, and

153 nitrogen $(\mathrm{N})$ as described below. 
155 Cross-inoculation test

156

157 Cross-inoculation tests were carried out to examine the effects of litter type,

158 incubation temperature, and origin of Mycena isolates on fungal decomposition.

159 Three fungal isolates (Mycena sp.2 from ST, $M$. polygramma from CT, and $M$.

160 aurantiidisca from SA) were inoculated onto leaves of three litter types

161 (Castanopsis sieboldii from ST, Fagus crenata from CT, and Betula ermanii from

$162 \mathrm{SA}$ ), and each combination of the three isolates $\times$ three litter types was incubated

163 at seven temperatures $\left(5,10,15,20,25,30\right.$, and $\left.35^{\circ} \mathrm{C}\right)$.

165 measured for the isolates of Mycena sp.2, M. polygramma, and $M$. aurantiidisca.

166 Mycelial disks of the three isolates, $6 \mathrm{~mm}$ in diameter, were taken from the edge of

167 cultures on Petri dishes containing 1\% MEA and incubated at $20^{\circ} \mathrm{C}$ for 2 weeks.

168 They were transferred to the center of another Petri dish $(9 \mathrm{~cm}$ in diameter)

169 containing $20 \mathrm{ml} \mathrm{1 \%}$ MEA. The plates were incubated at one of the seven

170 temperatures in the dark. Colony diameter was measured in two directions at 
171 right angles from each other three to five times at given intervals during a

172 3-month incubation, and colony diameter growth rate was calculated by

173 regressing the colony diameter against the days after inoculation. Four plates

174 were prepared for each isolate.

175

The decomposition tests were performed as described above, except that

176 the plates were incubated at one of the seven temperatures. The initial litter, the

177 control litter, and the litter with at least 5.0\% mass loss were used for the analysis

178 of AUR as described below.

179

180 Chemical analyses

181

182 Litter materials were combined to make one sample for each test and ground in a

183 laboratory mill (0.5 $\mathrm{mm}$ screen). The amount of AUR in the samples was

184 estimated by means of gravimetry as acid-insoluble residue, using hot sulfuric

185 acid digestion (King and Heath 1967). Samples were extracted with

186 alcohol-benzene at room temperature $\left(15-20^{\circ} \mathrm{C}\right)$, and the residue was treated with

$18772 \%$ sulfuric acid (v/v) for $2 \mathrm{~h}$ at room temperature with occasional stirring. The 
188 mixture was diluted with distilled water so that the concentration of sulfuric acid

189 reached $2.5 \%$ and autoclaved at $120^{\circ} \mathrm{C}$ for $60 \mathrm{~min}$. After cooling, the residue was

190 filtered and washed with water through a porous crucible $(\mathrm{G} 4)$, dried at $105^{\circ} \mathrm{C}$ and

191 weighed as acid-insoluble residue. The filtrate (autoclaved sulfuric acid solution)

192 was subjected to total carbohydrate analysis. The amount of carbohydrate in the

193 filtrate was estimated by means of the phenol-sulfuric acid method (Dubois et al.

194 1956). One milliliter of $5 \%$ phenol (v/v) and $5 \mathrm{ml}$ of $98 \%$ sulfuric acid (v/v) were

195 added to the filtrate. The optical density of the solution was measured using a

196 spectrophotometer at $490 \mathrm{~nm}$, using known concentrations of $\mathrm{D}^{\text {-glucose as }}$

197 standards. Total N content was measured by automatic gas chromatography (NC

198 analyzer SUMIGRAPH NC-900, Sumitomo Chemical Co., Osaka, Japan).

Mass loss of AUR was determined as a percentage of the original mass,

200 taking the mass loss of AUR in the uninoculated and incubated control treatment

201 into account. AUR/litter mass (AUR/L) loss ratio is a useful index of the selective

202 delignification caused by each fungal species (Osono and Hirose 2009). AUR/L loss

203 ratio of each fungal species was calculated using the equation: 
205 of litter (\% of original litter mass)

206

207 Statistical analysis

208

209 In the litter type test, Pearson's correlation coefficients were calculated for linear

210 relationships between chemical properties of litter and mass loss of the litter

211 caused by macrofungal isolates. In the cross inoculation test, factors affecting the

212 mass loss of litter were analyzed with generalized linear models (GLMs) with

213 fungal species, litter type, incubation temperature, and their interactions as

214 categorical predictors. Factors affecting the mass loss of AUR and AUR/L loss

215 ratio were also analyzed with GLMs with litter type and incubation temperature

216 as categorical predictors, but only the data of Mycena sp.2 were used because the

217 numbers of samples of $M$. polygramma and $M$. aurantiidisca used for AUR

218 analysis were too low. Tukey's HSD test was used for multiple comparisons. JMP

2196.0 for Macintosh was used to perform these analyses. 
223 Litter mass loss in the litter type test

224

225 To examine the effect of litter types and possible effects of chemical components

226 on fungal decomposition, six fungal isolates were inoculated onto multiple litter

227 types that differed in chemical properties and incubated at $20^{\circ} \mathrm{C}$, and the mass

228 loss of litter during the incubation was related to the chemical composition of the

229 litters. The initial content of AUR in leaf litter of a total of 39 litter types used in

230 the tests ranged from $8.8 \%$ to $45.6 \%$, that of total carbohydrates from $20.1 \%$ to

$23144.9 \%$, that of extractives from $5.3 \%$ to $20.6 \%$, and that of $\mathrm{N}$ from $0.41 \%$ to $1.75 \%$

232 (see Table S1).

233

Overall, the mean mass loss of litter caused by six fungal isolates ranged

234 from $-2.8 \%$ to $50.7 \%$ (see Table S1), indicating that there were large variations of

235 decomposition between litter types caused by fungal isolates. Three significant

236 correlation coefficients were detected out of a total of 24 combinations (six fungal

237 isolates $\times$ four chemical properties) (Table 1). Mass loss of litter caused by Mycena

238 sp.2 from ST and $M$. polygramma from CT was significantly and negatively 
239 correlated with AUR content in litter; and that caused by $M$. epipterygia from SA

240 was significantly and negatively correlated with the content of extractives and

241 significantly and positively correlated with $\mathrm{N}$ content (Fig. 1).

242

243 Colony diameter growth rate as related to temperature

244

245 The colony diameter growth rate increased linearly with temperature from 5 to

$24625^{\circ} \mathrm{C}$ for Mycena sp.2 from ST and from 5 to $20^{\circ} \mathrm{C}$ for $M$. polygramma from CT and

247 M. aurantiidisca from SA (Fig. 2). The optimal growth rate occurred at $25^{\circ} \mathrm{C}$ for

248 Mycena sp.2 and at $20^{\circ} \mathrm{C}$ for $M$. polygramma and $M$. aurantiidisca. The growth

249 rate was lower at temperatures above the optimal temperature. At $25^{\circ} \mathrm{C}, M$.

250 aurantiidisca displayed more severely reduced growth than $M$. polygramma.

251 Mycena sp.2 was the only isolate that grew at $30^{\circ} \mathrm{C}$. No growth occurred at $35^{\circ} \mathrm{C}$

252 for the three isolates.

253

254 Litter mass loss in the cross inoculation test 
256 Overall, the mean value of mass loss of litter ranged from $-1.4 \%$ to $54.4 \%$ (Fig. 3 ,

257 upper). Fungal isolate, litter type, incubation temperature, and their interactions

258 significantly affected the mass loss of litter during the incubation (Table 2A). The

259 mass loss of litter was in the order: Mycena sp.2 $>M$. polygramma $>M$.

260 aurantiidisca, and Betula> Castanopsis, Fagus. The mass loss of litter increased

261 with temperature: from $5^{\circ} \mathrm{C}$ to $25^{\circ} \mathrm{C}$ for Mycena sp.2 and $M$. polygramma and

262 from $10^{\circ} \mathrm{C}$ to $20^{\circ} \mathrm{C}$ for $M$. aurantiidisca. The greatest values of mass loss were

263 found at $25^{\circ} \mathrm{C}$ for Mycena sp.2 and at $20^{\circ} \mathrm{C}$ and $25^{\circ} \mathrm{C}$ for $M$. polygramma, and at

$26420^{\circ} \mathrm{C}$ for $M$. aurantiidisca, which were generally consistent with the optimum

265 temperatures of colony diameter growth rate of these isolates (Fig. 2). Mass loss of

266 litter was negligible at $5^{\circ} \mathrm{C}$ for all three isolates and at $35^{\circ} \mathrm{C}$ for $M y c e n a \mathrm{sp} .2$, at

$26730^{\circ} \mathrm{C}$ to $35^{\circ} \mathrm{C}$ for $M$. polygramma, and at $25^{\circ} \mathrm{C}$ to $35^{\circ} \mathrm{C}$ for $M$. aurantiidisca (Fig. 3 ).

269 Mycena isolates, and the interactions between temperature and fungal isolate and

270 between temperature and litter type were also significant (Fig. 3; Table 2),

271 indicating that the temperature effect depended on the fungal isolates and litter

272 types. For example, the changes in the mass loss of litter in relation to 
273 temperature were larger for Mycena sp.2, which had greater ability to cause mass

274 loss than $M$. polygramma and $M$. aurantiidisca, while these changes were less

275 obvious when the fungal isolates were inoculated onto Fagus litter, which was

276 more recalcitrant than Castanopsis and Betula litters.

277

278 AUR decomposition in the cross inoculation test

279

280 The litters with more than 5.0\% mass loss were analyzed for the mass loss of AUR.

281 The mean value of mass loss of AUR ranged from $2.6 \%$ to $68.9 \%$ (Fig. 3, middle).

282 Litter type and incubation temperature significantly affected the mass loss of

283 AUR caused by Mycena sp.2 during the incubation (Table 2B). Mass loss of AUR

284 by Mycena sp.2 was lower at $10^{\circ} \mathrm{C}$ than at 15 to $30^{\circ} \mathrm{C}$ and was higher on Betula

285 than on Fagus and Castanopsis.

The mean values of AUR/L loss ratio ranged from 0.3 to 2.6 (Fig. 3, lower).

287 Litter type significantly affected AUR/L loss ratio for Mycena sp.2, whereas

288 incubation temperature had no significant effect on AUR/L loss ratio (Table 2B). 


\section{Discussion}

291

292 The decomposition of litter by Mycena isolates varied with litter type (Tables S1,

293

2), and the extent of decomposition in various litter types was correlated

294 negatively with the contents of AUR or extractives and positively with $\mathrm{N}$ content

295 (Fig. 1; Table 1). Recalcitrant compounds in leaves designated as AUR, such as

296 lignin and tannin, have often been shown to limit the rate of decomposition in

297 forest soils (Geng et al. 1993; Stump and Binkley 1993; Murphy et al. 1998; Osono

298 and Takeda 2005) and of litter decomposition by ligninolytic fungi under pure

299 culture conditions (Osono et al. 2011b, 2011c; Hagiwara et al. 2012). Extractives

300 include soluble polyphenols, hydrocarbons, and pigments that are often released

301 rapidly from decomposing litter (Osono et al. 2014), and can include inhibitory

302 substances for fungal growth (Hughes et al. 2007). Nitrogen is a major essential

303 element limiting fungal growth and enzyme production and was found to be

304 positively related to mass loss caused by ligninolytic fungi (Osono et al. 2011b).

$25^{\circ} \mathrm{C}$ (Figs. 2 and 3), respectively, indicate that the Mycena isolates used are 
307 mesophilic. The isolate from cooler regions was more sensitive to higher

308 temperature than the isolate from warmer regions (Fig. 2), suggesting

309 physiological adaptations of these fungi to the climatic conditions of the respective

310 study sites (subtropical versus cool temperate versus subalpine). The optimal

311 temperature of hyphal growth was generally consistent with that of

312 decomposition, which agrees with the finding of Osono et al. (2011c) for three

313 isolates of Xylaria sp. from CT.

314 Incubation temperature affected the mass loss of litter by the three

315 Mycena isolates and the mass loss of AUR by Mycena sp.2 (Fig. 3; Table 2).

316 However, AUR/L loss ratio of Mycena sp.2 was not affected by incubation

317 temperatures (Table 2), suggesting that the degree of selective AUR

318 decomposition by Mycena sp.2 was insensitive to the range of temperature

319 adopted in the present study. Previously, Adaskaveg et al. (1995) and Osono et al.

320 (2011c) reported that at temperatures above the optimum growth temperatures,

321 the ligninolytic activity of fungi increased at the expense of cellulolytic activity,

322 resulting in suppressed overall decomposition of leaf litter. My finding here for

323 Mycena sp.2 from ST suggested that the sensitivity of selective delignification to 
324 temperature could vary with fungal species. Osono and Takeda (2006) also

325 showed that the degree of selective delignification caused by four ligninolytic

326 fungi did not differ between incubation at $10^{\circ} \mathrm{C}$ or $20^{\circ} \mathrm{C}$, whereas Gymnopus

327 dryophilus decomposed AUR more selectively at $10^{\circ} \mathrm{C}$ than at $20^{\circ} \mathrm{C}$. More studies

328 are needed to evaluate the sensitivity to temperature of ligninolytic activity of

329 litter-decomposing macrofungi, including those from cooler regions, such as $M$.

330 polygramma and $M$. aurantiidisca.

The three Mycena isolates from different climates differed significantly

332 in their ability to decompose litter and in AUR and AUR/L loss ratio (Fig. 3, Table

333 2). This difference in decomposing ability was within the range of variability

334 found for a suite of Mycena species encountered at these sites. That is, Osono

335 (submitted) compared the ability of 32 Mycena isolates from ST, CT, and SA to

336 decompose leaf litter and demonstrated a similar variation in decomposing ability

337 among the climatic regions. The results of the present study were consistent with

338 those of Osono (submitted) showing that some Mycena species generally are

339 active decomposers of AUR. Mycena polygramma IFO33011 from CT is an outlier

340 as this isolate has been reported to decompose cellulose selectively over AUR 
341 (Osono and Takeda 2002; Osono et al. 2003).

342

The effects of litter type, origin of isolate, and temperature on the

343 decomposition of leaf litter by ligninolytic Mycena and other LDM may have

344 implications regarding the changes in fungal decomposition of leaf litter in

345 relation to climatic conditions. First, the variation of decomposition of litter

346 between the fungal isolates was larger than the variations with temperature and

347 litter type (Table 2), suggesting that a shift in fungal species composition can

348 affect the decomposition at the level of LDM assemblages more than changes in

349 temperature and/or litter. Studying the species composition of fungal assemblages,

350 decomposing abilities of individual fungal species, and their geographical

351 distributions is thus crucial for predicting the response of fungal decomposition to

352 possible climate changes. However, studies on the geographical distribution of

353 litter-decomposing fungi are still scarce (e.g. Iwamoto and Tokumasu 2001;

354 Tokumasu 2001; Hosoya et al. 2010). Further studies are needed to examine the

355 geographical distribution of fungi in conjunction with their decomposing abilities. Secondly, the ability of individual Mycena species to decompose litter and

357 AUR also varied with temperature and litter type (Table 2; Fig. 1). This suggests 
358 that the functioning of LDM could change along with a possible future increase in

359 temperature worldwide, which in temperate regions is expected to be an increase

360 of $2-3^{\circ} \mathrm{C}$ (Manabe et al. 1991; Boer et al. 1992; Russell et al. 1995) and/or with

361 concomitant changes in vegetation (Tsukada 1983; Matsui et al. 2004). For

example, an increase of litter temperature to optimum growth temperatures could

363 lead to enhanced decomposition by LDM, resulting in positive feedback to the

364 atmospheric $\mathrm{CO}_{2}$ level. An increase in the relative abundance of tree species with

365 low AUR content in litter might have a similar positive feedback. These

366 predictions are obviously oversimplified, but data such as the results of the

367 present study will provide useful insights into the possible effects of future

368 climate changes on fungal decomposition in forest soils.

369

370 Acknowledgments

I thank Mr. Y. Hagiwara for help with chemical

371 analyses; and Dr. Elizabeth Nakajima for critical reading of the manuscript. This

372 study received partial financial support from the Ministry of Education, Culture,

373 Sports, Science, and Technology of Japan (MEXT) (No. 19780114), The Sumitomo

374 Foundation, Nissan Global Foundation, Nippon Life Inst. Foundation, and the 
375 Grants for Excellent Graduate Schools, MEXT, Japan (12-01) to Kyoto University.

376

$377 \quad$ References

378

379 Adaskaveg JE, Gilbertson RL, Dunlap MR (1995) Effects of incubation time and temperature on in vitro selective delignification of silver leaf oak by Ganoderma colossum. Appl Environ Microbiol 61:138-144

382

383 commonly detected in Pinus sylvestris needle litter. Fungal Ecol $4: 110-114$

385 Boer GJ, McFarlane NA, Lazare M (1992) Greenhouse gas-induced climate change simulated with the CCC second-generation general circulation model. J Climate 5:1045-1077

388 Dubois M, Gilles KA, Hamilton JK, Rebers PA, Smith F (1956) Colorimetric 389 method for determination of sugars and related substances. Anal Chem

390 28:350-356

391 Geng X, Pastor J, Dewey B (1993) Decay and nitrogen dynamics of litter from 
disjunct, congeneric tree species in old-growth stands in northeastern

China and Wisconsin. Can J Bot 71:693-699

394 Hagiwara Y, Osono T, Ohta S, Agus W, Hardjono A (2012) Colonization and decomposition of leaf litter by ligninolytic fungi in Acacia mangium 396 plantations and adjacent secondary forests. J For Res 17:51-57

397 Hosoya T, Hirose D, Fujisaki M, Osono T, Kubono T, Tokumasu S, Kakishima M 398 (2010) Internal transcribed spacer haplotype diversity and their geographical distribution in Dasyscyphella longistipitata (Hyaloscyphaceae, Helotiales) occurring on Fagus crenata cupules in Japan. Mycoscience 51:116-122

402 Hughes KA, Bridge P, Clark MS (2007) Tolerance of Antarctic soil fungi to 403 hydrocarbons. Sci Total Environ 372:539-548

404 Iwamoto S, Tokumasu S (2001) Dematiaceous hyphomycetes inhabiting decaying 405 blackish needles of Abies firma and their distribution in the Kanto district, Japan. Mycoscience 42:273-279

407 King HGC, Heath GW (1967) The chemical analysis of small samples of leaf material and the relationship between the disappearance and 
410 Lindahl B, Boberg J (2008) Distribution and function of litter basidiomycetes in coniferous forests. In: Boddy L, Frankland JC, van West P (eds) Ecology of Saprotrophic Basidiomycetes. Academic Press, London, pp. 183-196

413 Lindeberg G (1946) On the decomposition of lignin and cellulose in litter caused by soil-inhabiting hymenomycetes. Ark Bot 33a:1-16 coupled ocean-atmosphere model to gradual changes of atmospheric $\mathrm{CO}_{2}$. Part I: Annual mean response. J Climate 4:785-818

418 Matsui T, Yagihashi T, Nakaya T, Taoda H, Yishinaga S, Daimaru H, Tanaka N (2004) Probability distributions, vulnerability and sensitivity in Fagus 15:605-614

422

Mikola P (1956) Studies on the decomposition of forest litter by basidiomycetes. Commun Inst For Fenn48:4-48 crenata forests following predicted climate changes in Japan. J Veg Sci litter-decomposing basidiomycetes from Picea forests of Hokkaido. 
427 Murphy KL, Klopatek JM, Klopatek CC (1998) The effects of litter quality and climate on decomposition along an elevational gradient. Ecol Appl 8:1061-1071

430 Osono $\mathrm{T}$ (2007) Ecology of ligninolytic fungi associated with leaf litter decomposition. Ecol Res 22:955-974

432 Osono $\mathrm{T}$ (2011) Diversity and functioning of fungi associated with leaf litter decomposition in Asian forests of different climatic regions. Fun Ecol $4: 375-385$

435 Osono T. Mycelial biomass in the forest floor and soil of subtropical, temperate, and subalpine forests. J For Res in press a

437 Osono T. Diversity, resource utilization, and phenology of fruiting bodies of litter-decomposing macrofungi in subtropical, temperate, and subalpine forests. J For Res in press b

440 Osono T. Decomposing ability of diverse litter-decomposer macrofungi in subtropical, temperate, and subalpine forests. J For Res submitted 
445 Osono T, Takeda H (2005) Decomposition of organic chemical components in relation to nitrogen dynamics in leaf litter of 14 tree species in a cool temperate forest. Ecol Res 20:41-49

Osono T, Takeda H (2006) Fungal decomposition of Abies needle and Betula leaf litter. Mycologia 98:172-179

Osono T, Hirose D (2009) Effects of prior decomposition of Camellia japonica leaf litter by an endophytic fungus on the subsequent decomposition by fungal colonizers. Mycoscience 50:52-55

453 Osono T, Fukasawa Y, Takeda H (2003) Roles of diverse fungi in larch needle litter decomposition. Mycologia 95:820-826

Osono T, Hobara S, Hishinuma T, Azuma JI (2011a) Selective lignin decomposition and nitrogen mineralization in forest litter colonized by Clitocybe sp. Eur J Soil Biol 47:114-121 
461 Osono T, Hagiwara Y, Masuya H (2011c) Effects of temperature and litter type on fungal growth and decomposition of leaf litter. Mycoscience 52:327-332

463

Osono T, Azuma JI, Hirose D (2014) Plant species effect on the decomposition and chemical changes of leaf litter in grassland and pine and oak forest soils. Plant Soil 376:411-421

Russell GL, Miller JR, Rind D (1995) A coupled atmosphere-ocean model for transient climate change studies. Atmos-Ocean 33:683-730

Steffen KT, Cajthaml T, Šnajdr J, Baldrian P (2007) Differential degradation of oak (Quercus petraea) leaf litter by litter-decomposing basidiomycetes. Res Microbiol 158:447-455 availability in Rocky Mountain forests. Can J For Res 23:492-502

Stump LM, Binkley D (1993) Relationships between litter quality and nitrogen availability in Rocky Mountain forests. Can J For Res 23:492-502 forests of Japan. Mycoscience 42:575-589 
477 Valášková V, Šnajdr J, Bittner B, Cajthaml T, Merhautová V, Hofrichter M,

478

479

480

481 Van der Wal A, Geydan TD, Kuyper TW, de Boer W (2013) A thready affair: decomposition processes. FEMS Microbiol Rev 37:477-494

484 Žifčáková L, Dobiášová P, Kolářová Z, Koukol O, Baldrian P (2011) Enzyme 485 486 Baldrian P (2007) Production of lignocellulose-degrading enzymes and degradation of leaf litter by saprotrophic basidiomycetes isolated from a Quercus petraea forest. Soil Biol Biochem 39:2651-2660 linking fungal diversity and community dynamics to terrestrial activities of fungi associated with Picea abies needles. Fungal Ecol $4: 427-436$ 
Osono Table 1

Table 1. Pearson's correlation coefficients for linear relationship between contents of organic chemical components and nitrogen in leaf litter and mass loss of leaf litter caused by isolates of macrofungi. ${ }^{* *} \mathrm{P}<0.001, * \mathrm{P}<0.05$, ns not significant.

\begin{tabular}{|c|c|c|c|c|c|c|c|c|c|}
\hline & Fungus & $\begin{array}{l}\text { Number of tree } \\
\text { species used }\end{array}$ & AUR & & Total carbohydrates & Extractives & & Nitrogen & \\
\hline $\mathrm{ST}$ & Mycena sp.1 & 12 & -0.51 & $\mathrm{~ns}$ & $0.06 \mathrm{~ns}$ & 0.05 & $\mathrm{~ns}$ & 0.21 & ns \\
\hline \multirow[t]{2}{*}{$\mathrm{CT}$} & Mycena polyramma & 15 & -0.80 & $* * *$ & $0.26 \mathrm{~ns}$ & 0.17 & $\mathrm{~ns}$ & -0.25 & ns \\
\hline & Clitocybe sp.1 & 15 & -0.36 & $\mathrm{~ns}$ & $0.22 \mathrm{~ns}$ & -0.27 & $\mathrm{~ns}$ & -0.14 & ns \\
\hline $\mathrm{SA}$ & Mycena epipterygia & 12 & 0.29 & $\mathrm{~ns}$ & $0.15 \mathrm{~ns}$ & -0.60 & $*$ & 0.57 & $*$ \\
\hline
\end{tabular}




\section{Osono Table 2}

Table 2. Results of generalized linear models (GLMs) examining the effect of fungal species, litter species, and temperature on litter mass loss (A), and examining the effect of litter species and temperature on AUR mass loss and AUR/litter mass (AUR/L) loss ratio for Mycena sp.2. *** $\mathrm{P}<0.001,{ }^{* *} \mathrm{P}<0.01,{ }^{*} \mathrm{P}<0.05$, ns not significant.

\begin{tabular}{lrrr}
\hline (A) Litter mass loss & d.f. & \multicolumn{1}{c}{$\chi^{2}$} \\
\hline Model & 62 & 504.7 & $* * *$ \\
Fungal isolate & 2 & 313.8 & $* * *$ \\
Litter type & 2 & 100.5 & $* * *$ \\
Temperature & 6 & 280.1 & $* * *$ \\
Fungal isolate $\times$ Litter type & 4 & 25.5 & $* * *$ \\
Fungal isolate $\times$ Temperature & 12 & 251.9 & $* * *$ \\
Litter type $\times$ Temperature & 12 & 63.5 & $* * *$ \\
Fungal isolate $\times$ Litter type $\times$ Temperature & 24 & 37.6 & $*$ \\
\hline
\end{tabular}

\begin{tabular}{|c|c|c|c|c|c|c|}
\hline \multirow[t]{2}{*}{ (B) } & \multicolumn{3}{|c|}{ AUR mass loss } & \multicolumn{3}{|c|}{ AUR/L loss ratio } \\
\hline & d.f. & $\chi^{2}$ & & d.f. & $\chi^{2}$ & \\
\hline Model & 6 & 41.2 & $* * *$ & 6 & 13.1 & $*$ \\
\hline Litter type & 2 & 22.7 & $* * *$ & 2 & 7.2 & * \\
\hline Temperature & 4 & 37.3 & $* * *$ & 4 & 8.6 & $\mathrm{~ns}$ \\
\hline
\end{tabular}


1 Figure legends.

2

3 Fig. 1. Mass loss of leaf litter caused by isolates of macrofungi as related to

4 contents of organic chemical components and nitrogen. ST, mass loss caused by

5 Mycena sp.2 was negatively correlated with AUR content in leaf litter of 12 tree

6 species. CT, mass loss caused by Mycena polygramma was negatively correlated

7 with AUR content in leaf litter of 15 tree species. SA, mass loss caused by Mycena epipterygia was negatively correlated with extractive content and positively

9 correlated with nitrogen content in 12 litter types. Correlation coefficients for the

10 relationships are shown in Table 1.

12 Fig. 2. Colony diameter growth rate of isolates of Mycena sp.2 ( $\square$, from ST), $M$. 13 polygramma ( $\bigcirc$, from $\mathrm{CT}$ ), and $M$. aurantiidisca ( $\boldsymbol{\Delta}$, from $\mathrm{SA}$ ) as related to 14 temperature. Bars indicate standard errors $(n=4)$.

16 Fig. 3. Mass loss of leaf litter (upper) and AUR (middle) and AUR/litter (AUR/L) 17 mass loss rate (lower) in leaf litter of Castanopsis sieboldii ( $\square$, from ST), Fagus 18 crenata $(\bigcirc$, from $\mathrm{CT})$, and Betula ermanii $(\boldsymbol{\Delta}$, from $\mathrm{SA})$ caused in vitro by isolates 19 of Mycena sp.2 (left, from ST), $M$. polygramma (center, from CT), and $M$. 20 aurantiidisca (right, from SA) at seven temperatures for 12 weeks in the dark.

21 Bars indicate standard errors $(n=3$ or 4$)$. 
1 Osono Fig. 1
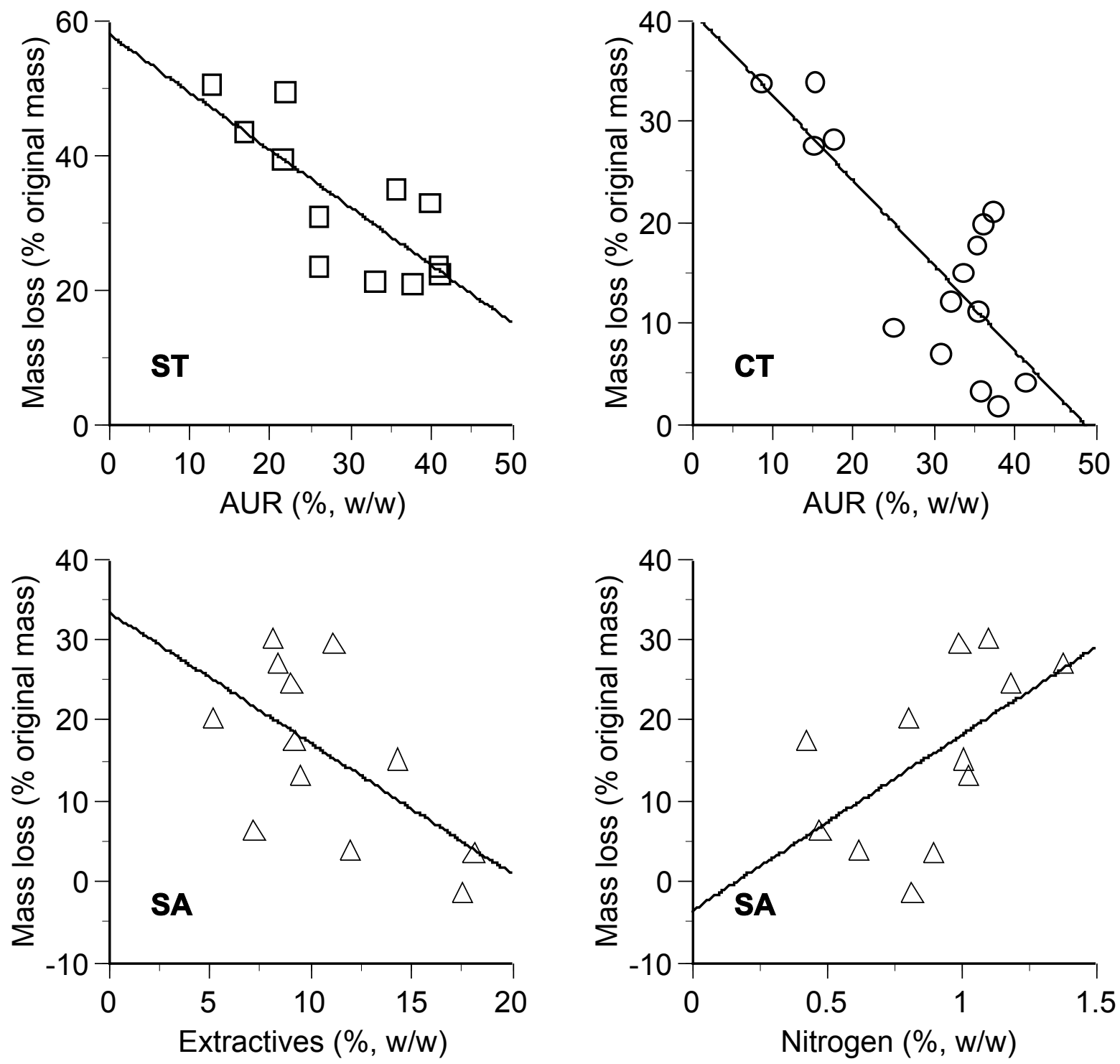
1 Osono Fig. 2

3

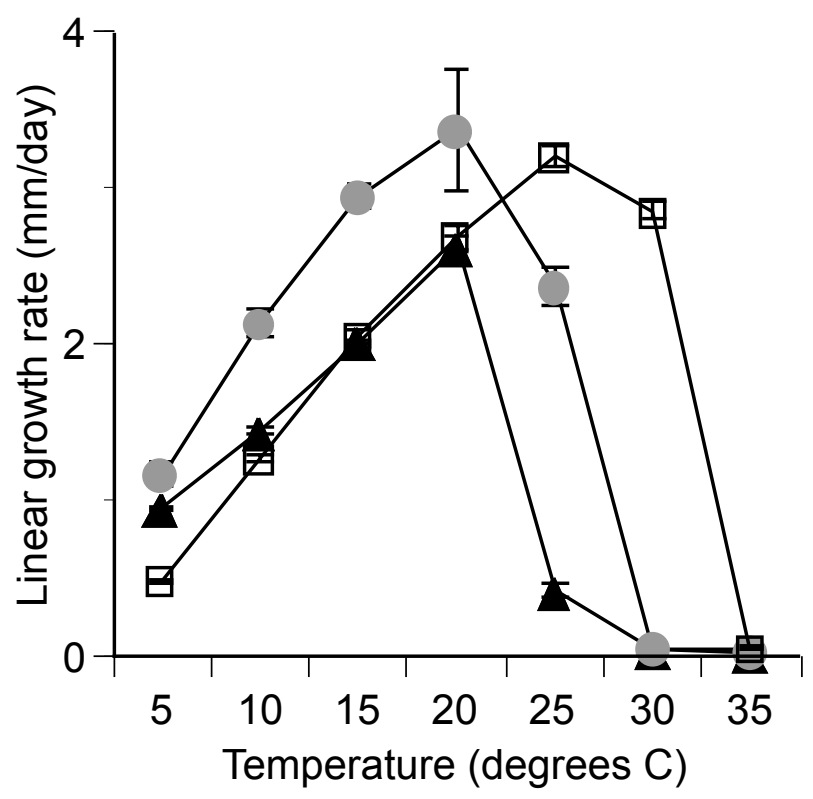


1 Osono Fig. 3
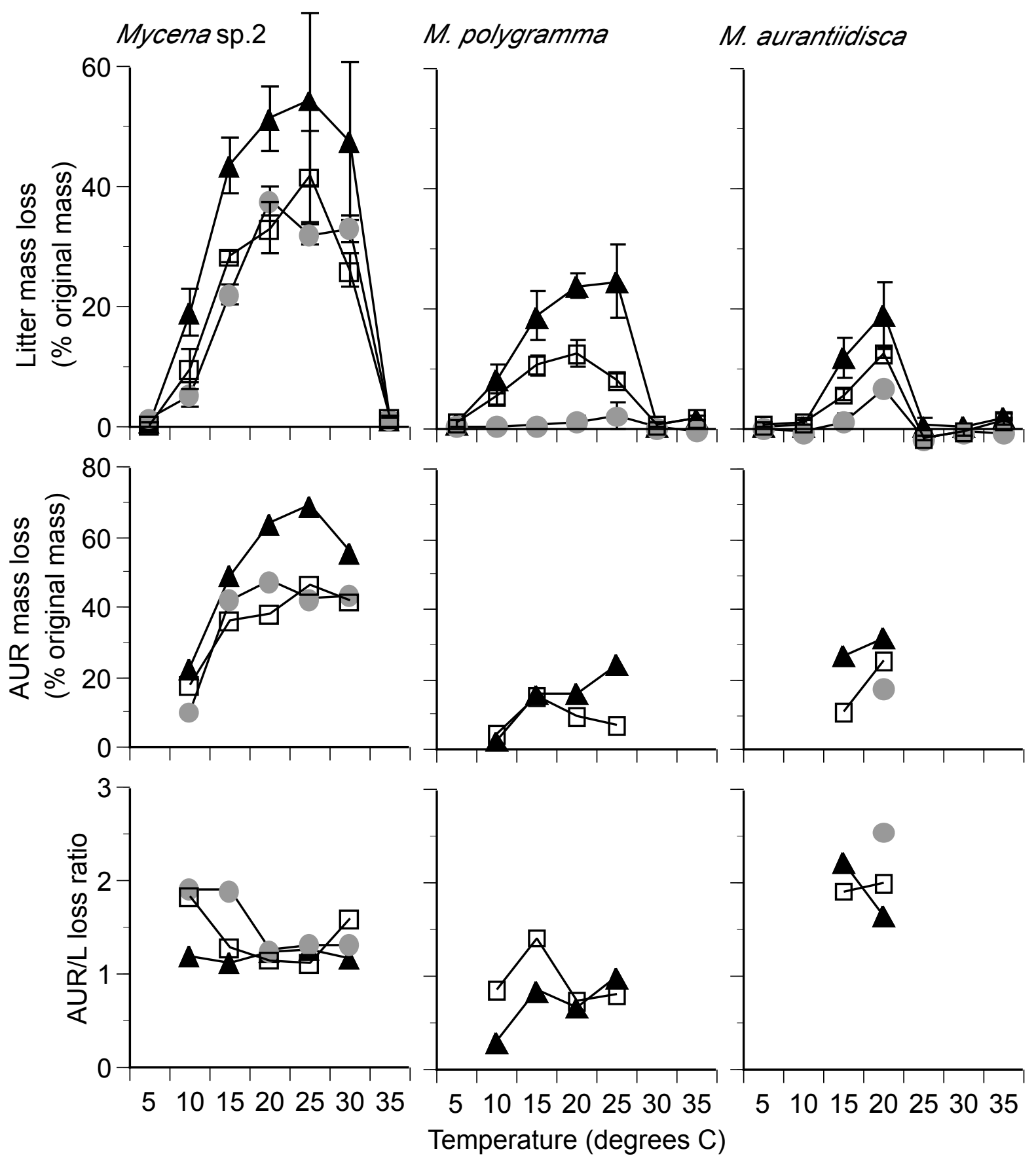


\section{Electronic Supplementary Material}

Effects of litter type, origin of isolate, and temperature on decomposition of leaf litter by macrofungi

Takashi Osono

Table S1. Contents of organic chemical components and nitrogen $(\% \mathrm{w} / \mathrm{w})$ and mass loss of leaf litter (\% original mass) caused by isolates of macrofungi in leaf litter of multiple litter types. AUR, acid unhydrolyzable residue; TCH, total carbohydrates; Extr, extractives; $\mathbf{N}$, nitrogen.

\begin{tabular}{|c|c|c|c|c|c|c|}
\hline Litter type & AUR & $\mathrm{TCH}$ & Extr & $\mathrm{N}$ & Mass loss & Mass loss \\
\hline Subtropical forest & & & & & Mycena sp.1 & Mycena sp.2 \\
\hline Schefflera octophylla & 21.7 & 32.0 & 20.6 & 0.69 & 35.6 & 39.3 \\
\hline Sapium japonicum & 13.0 & 43.5 & 9.3 & 0.58 & 35.3 & 50.7 \\
\hline Dendropanax trifidus & 22.0 & 35.6 & 11.3 & 0.55 & 33.1 & 49.6 \\
\hline Malotus japonicus & 17.0 & 33.8 & 10.2 & 1.03 & 32.1 & 43.4 \\
\hline Heterosmilax japonica & 40.0 & 36.7 & 5.9 & 0.72 & 28.5 & 33.0 \\
\hline Pinus luchuensis & 41.2 & 44.9 & 6.0 & 0.41 & 26.4 & 22.3 \\
\hline Schima wallichii & 35.8 & 29.7 & 10.7 & 0.52 & 26.3 & 34.9 \\
\hline Castanopsis sieboldii & 26.2 & 34.5 & 11.2 & 0.62 & 23.1 & 30.8 \\
\hline Syzygium buxifolium & 41.1 & 27.0 & 11.8 & 0.47 & 22.5 & 23.7 \\
\hline Podocarpus macrophyllus & 33.1 & 43.3 & 6.5 & 0.47 & 19.9 & 21.4 \\
\hline Quercus miyagii & 37.8 & 30.3 & 14.9 & 0.71 & 14.3 & 21.0 \\
\hline Daphniphyllum teijismannii & 26.1 & 39.2 & 12.5 & 0.61 & 12.0 & 23.7 \\
\hline Cool temperate forest & & & & & Mycena polygramma & Clitocybe sp. \\
\hline Malotus japonicus & 15.4 & 27.1 & 17.3 & 1.20 & 34.0 & 3.9 \\
\hline Benthamidia kousa & 8.8 & 32.8 & 11.3 & 1.04 & 33.9 & 8.9 \\
\hline Carpinus laxiflora & 17.8 & 32.6 & 11.5 & 1.25 & 28.3 & 10.2 \\
\hline Acer micranthum & 15.3 & 32.3 & 12.5 & 0.78 & 27.7 & 9.6 \\
\hline
\end{tabular}




\begin{tabular}{|c|c|c|c|c|c|c|}
\hline Quercus serrata & 37.4 & 26.3 & 8.0 & 0.94 & 21.1 & 5.4 \\
\hline Betula grossa & 36.2 & 26.7 & 7.0 & 1.12 & 19.9 & 11.8 \\
\hline Weigela hortensis & 35.5 & 28.6 & 9.9 & 0.95 & 17.8 & 0.4 \\
\hline Acer rufinerve & 33.7 & 27.0 & 15.0 & 0.78 & 15.1 & 8.0 \\
\hline Castanea crenata & 32.2 & 29.6 & 8.6 & 1.14 & 12.3 & 9.9 \\
\hline Quercus crispula & 35.6 & 29.6 & 9.7 & 0.99 & 11.2 & 6.6 \\
\hline Malus tschonoskii & 25.1 & 37.6 & 12.4 & 0.79 & 9.6 & 2.5 \\
\hline Magnolia obovata & 31.0 & 31.4 & 10.4 & 1.04 & 7.1 & 9.5 \\
\hline Fagus crenata & 41.5 & 28.9 & 8.8 & 1.68 & 4.2 & 1.1 \\
\hline Pterocarya rhoifolia & 35.9 & 25.0 & 11.5 & 1.75 & 3.4 & 4.8 \\
\hline Aesculus turbinata & 38.0 & 23.5 & 15.1 & 0.89 & 1.9 & 1.1 \\
\hline Subalpine forest & & & & & Mycena aurantiidisca & Mycena epipterygia \\
\hline Betula ermanii & 45.6 & 29.1 & 8.2 & 1.10 & 36.7 & 30.4 \\
\hline Sorbus commixta & 30.6 & 33.0 & 11.2 & 1.00 & 35.9 & 29.8 \\
\hline Sorbus japonicum & 31.9 & 37.0 & 8.5 & 1.38 & 22.2 & 27.2 \\
\hline Reynoutria japonica & 44.8 & 31.1 & 5.3 & 0.81 & 20.3 & 20.5 \\
\hline Aralia cordata & 23.9 & 25.9 & 9.6 & 1.03 & 16.6 & 13.4 \\
\hline Vibrnum furcatum & 29.8 & 36.5 & 9.1 & 1.19 & 12.9 & 24.7 \\
\hline Sasa kurilensis & 23.1 & 41.1 & 7.3 & 0.48 & 8.3 & 6.6 \\
\hline Salix sachaliensis & 42.6 & 20.1 & 14.4 & 1.01 & 7.7 & 15.3 \\
\hline Pinus pentaphylla & 42.1 & 36.1 & 9.3 & 0.43 & 6.3 & 17.6 \\
\hline Picea jezoensis var. hondoensis & 34.4 & 36.3 & 17.6 & 0.82 & 1.1 & -1.1 \\
\hline Tsuga diversiflora & 38.5 & 25.1 & 18.1 & 0.90 & 0.9 & 3.7 \\
\hline Cercidiphyllum japonicum & 25.7 & 23.9 & 12.0 & 0.62 & -2.8 & 4.1 \\
\hline
\end{tabular}

